\title{
Overexpression of the Gene Encoding Neurosecretory Protein GL Precursor Prevents Excessive Fat Accumulation in the Adipose Tissue of Mice Fed a Long-Term High-Fat Diet
}

\author{
Keisuke Fukumura ${ }^{*}{ }^{\dagger}$, Yuki Narimatsu ${ }^{\dagger}$, Shogo Moriwaki, Eiko Iwakoshi-Ukena, Megumi Furumitsu \\ and Kazuyoshi Ukena *iD
}

check for updates

Citation: Fukumura, K.; Narimatsu, Y.; Moriwaki, S.; Iwakoshi-Ukena, E.

Furumitsu, M.; Ukena, K.

Overexpression of the Gene Encoding

Neurosecretory Protein GL Precursor

Prevents Excessive Fat Accumulation in the Adipose Tissue of Mice Fed a Long-Term High-Fat Diet. Molecules 2021, 26, 6006. https://doi.org/ $10.3390 /$ molecules26196006

Academic Editor: Claudio Ferrante

Received: 31 August 2021

Accepted: 30 September 2021

Published: 3 October 2021

Publisher's Note: MDPI stays neutral with regard to jurisdictional claims in published maps and institutional affiliations.

Copyright: (c) 2021 by the authors. Licensee MDPI, Basel, Switzerland. This article is an open access article distributed under the terms and conditions of the Creative Commons Attribution (CC BY) license (https:// creativecommons.org/licenses/by/ $4.0 /)$.
Laboratory of Neurometabolism, Graduate School of Integrated Sciences for Life, Hiroshima University, Higashi-Hiroshima, Hiroshima 739-8521, Japan; d214243@hiroshima-u.ac.jp (Y.N.); m203300@hiroshima-u.ac.jp (S.M.); iwakoshi@hiroshima-u.ac.jp (E.I.-U.); mfurumi@hiroshima-u.ac.jp (M.F.)

* Correspondence: kfuku@hiroshima-u.ac.jp (K.F.); ukena@hiroshima-u.ac.jp (K.U.)

† These authors contributed equally to this work.

Abstract: We previously identified a novel small hypothalamic protein, neurosecretory protein GL (NPGL), which induces feeding behavior and fat accumulation in rodents depending on their diet. In the present study, we explored the effects of NPGL on feeding behavior and energy metabolism in mice placed on a long-term high-fat diet with 60\% calories from fat (HFD 60). Overexpression of the NPGL precursor gene ( $\mathrm{Npgl}$ ) over 18 weeks increased food intake and weight. The weekly weight

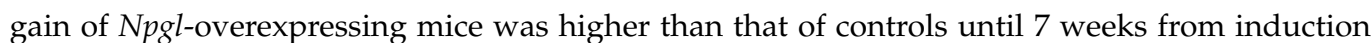
of overexpression, after which it ceased to be so. Oral glucose tolerance tests showed that $N p g l$ overexpression maintained glucose tolerance and increased blood insulin levels, and intraperitoneal insulin tolerance tests showed that it maintained insulin sensitivity. At the experimental endpoint, $\mathrm{Npgl}$ overexpression was associated with increased mass of the perirenal white adipose tissue (WAT) and decreased mass of the epididymal WAT (eWAT), resulting in little effect on the total WAT mass. These results suggest that under long-term HFD 60 feeding, Npgl overexpression may play a role in avoiding metabolic disturbance both by accelerating energy storage and by suppressing excess fat accumulation in certain tissues, such as the eWAT.

Keywords: neurosecretory protein GL; hypothalamus; neuropeptide; obesity; insulin sensitivity; glucose tolerance

\section{Introduction}

Obesity has become a public health problem of global scale. Treatment of this increasingly prevalent disease presents a vast economic burden, and there are no definitive therapeutic approaches. Obesity is regulated by genetic and environmental factors and is often accompanied by comorbidities, such as depression, type 2 diabetes, cardiovascular disease, and certain cancers [1-3]. As obesity progresses, excess fat accumulation induces chronic inflammation in adipose tissue, leading to systemic insulin resistance and glucose intolerance $[4,5]$. It is known that excessive and picky feeding behaviors, such as continuous consumption of a high-fat diet (HFD), can lead to metabolic disturbances; therefore, the mechanisms controlling feeding behavior and metabolism have been intensely studied [6-8]. Several neuropeptides regulating feeding behavior and metabolism have been discovered in the arcuate nucleus of the hypothalamus, including potent orexigenic and anorexigenic factors such as neuropeptide Y (NPY), agouti-related peptide (AgRP), and proopiomelanocortin (POMC)-derived $\alpha$-melanocyte-stimulating hormone [6-8]. In addition, some studies have reported that some of these neuropeptides, such as NPY, play a crucial role not only in feeding behavior but also in the regulation of systemic insulin sensitivity [9]. Peripheral factors in regulation of feeding include ghrelin and 
leptin, which are also peptides. Ghrelin, an orexigenic peptide produced by the stomach, stimulates feeding behavior through NPY/AgRP neurons [10-12]. Conversely, leptin is anorexigenic and is secreted from the white adipose tissue (WAT); it influences the activity of NPY / AgRP and POMC neurons [13-15]. Like the hypothalamic neuropeptides, ghrelin, and leptin are recognized as causal factors that influence systemic insulin sensitivity and glucose tolerance $[16,17]$. Insulin, secreted from the $\beta$-cells of the pancreas, converts dietary carbohydrates into fat reserves in peripheral tissues, thus maintaining blood glucose homeostasis $[18,19]$.

Although the central and peripheral factors involved in energy homeostasis have been identified, the hormonal controls underlying the development of obesity and its comorbid conditions, such as insulin resistance and glucose intolerance, are not fully understood. In the course of our investigations of the regulatory mechanisms of energy homeostasis, we previously identified a novel cDNA encoding a peptide hormone precursor in the chick hypothalamus [20]. The novel peptide hormone, a small secretory protein of 80 amino acids with a Gly-Leu- $\mathrm{NH}_{2}$ sequence at the C-terminus, has been named neurosecretory protein GL (NPGL) [20]. Homologous NPGL proteins have been discovered in mammals, including humans, rats, and mice, suggesting that NPGL is highly conserved and executes a vital function across species [21]. Although the receptor for NPGL remains unknown, NPGL-producing cells are located in the lateroposterior region of the hypothalamic arcuate nucleus of rodents [22,23]. Intracerebroventricular (i.c.v.) infusion of NPGL increases food intake and alters energy metabolism in avian species [24,25]. Likewise, acute i.c.v. infusion of NPGL increases food intake in mice [22], and chronic i.c.v. infusion of NPGL in mice increases food intake and results in considerable fat accumulation in adipose tissue [26]. We have also shown that overexpression of the NPGL precursor gene ( $N p g l$ elicits food intake and subsequent fat accumulation in the WAT of rats through de novo lipogenesis using dietary carbohydrates [23]. Chronic i.c.v. infusion of NPGL induces fat accumulation in the WAT of rats fed a high-sucrose diet, but it does not affect the WAT mass in rats fed an HFD with 60\% calories from fat (HFD 60) [27]. In a recent study, we have subjected

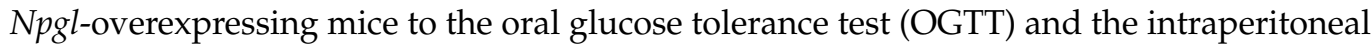
insulin tolerance test (IPITT) under normal chow (NC) for 4 weeks and subsequent HFD with $45 \%$ calories from fat (HFD 45) for 4 weeks [28]. The study has shown that Npgl overexpression can improve insulin resistance and glucose intolerance under HFD 45, switched from NC feeding [28]. In addition, we observed no fat accumulation in the WAT

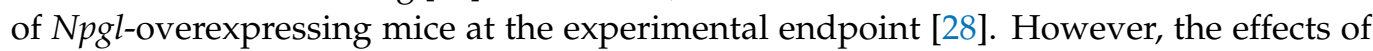
NPGL on feeding behavior and energy metabolism under a continuous HFD feeding, which is sufficient to induce diet-induced obesity and metabolic abnormalities, remain unclear.

In this study, we induced obesity in Npgl-overexpressing mice by long-term HFD 60 feeding in order to investigate the effects of $\mathrm{Npgl}$ overexpression on weight, food intake, tissue and organ mass, blood biomarkers, and mRNA expression of genes regulating lipid metabolism. In addition, we evaluated the glucose tolerance and insulin sensitivity of Npgl-overexpressing mice by performing the OGTT and the IPITT.

\section{Results}

\subsection{Food Intake and Weight}

We performed stereotaxic surgery to induce $\mathrm{Npgl}$ overexpression in the mediobasal hypothalamus (MBH) of HFD 60-fed mice using an adeno-associated virus (AAV) vector, then conducted a series of experiments to explore the effects of $\mathrm{Npgl}$ overexpression on feeding behavior, metabolism, glucose tolerance, and insulin sensitivity (Figure 1A). At the experimental endpoint, we used quantitative RT-PCR to confirm that Npgl overexpression had been successfully induced by the AAV vector (Figure S1). Npgl overexpression resulted in significantly increased weekly and cumulative food intake for 18 weeks after surgery (Figure 1B,C). Furthermore, Npgl-overexpressing mice exhibited increased weight and appeared obese (Figure 1D,E). However, after 7 weeks post-surgery, the weekly weight gain of Npgl-overexpressing mice ceased to be elevated in comparison with controls (Figure 1F). 
A

\begin{tabular}{|ccccc|}
\hline & 0 & 5 & 16 & 17 \\
\hline & & HFD 60 feeding & $(\mathrm{w})$ \\
\hline & $\uparrow$ & $\uparrow$ & $\uparrow$ & $\uparrow$ \\
Stereotaxic surgery for & $\uparrow_{\text {OGTT }}^{-3}$ & $\uparrow_{\text {IPITT }}$ & & \\
\hline OGTT IPITT
\end{tabular}

Npgl overexpression

B

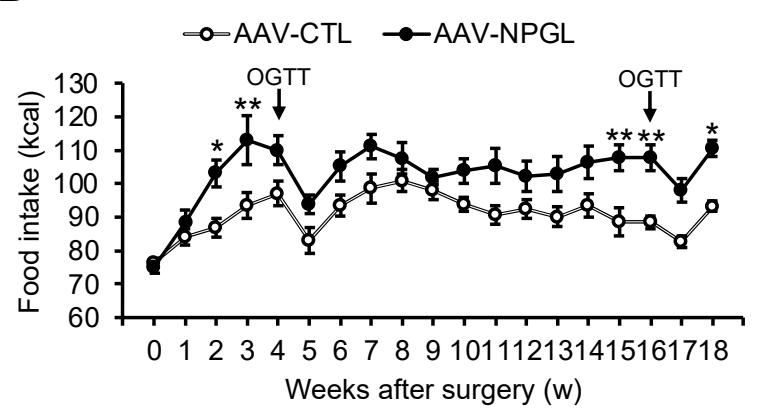

$E$

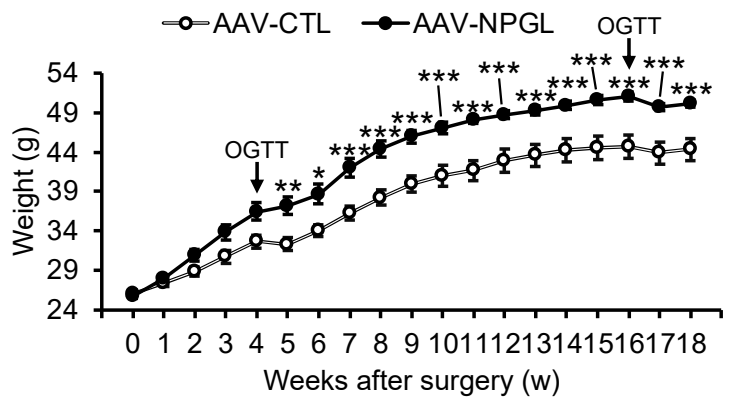

C

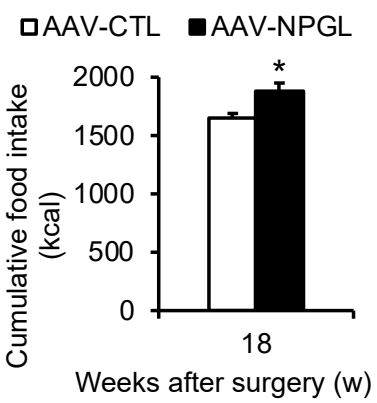

F

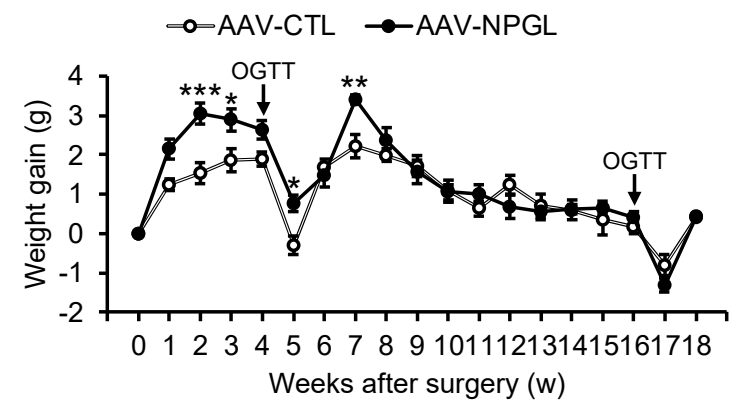

Figure 1. Effects of $\mathrm{Npgl}$ overexpression on weight gain and food intake in mice fed a high-fat diet with $60 \%$ calories from fat (HFD 60). These mice were injected with an adeno-associated virus (AAV) vector, either a control (AAV-CTL) or a vector carrying the NPGL precursor gene (AAV-NPGL). (A) Experimental procedure. Mice were subjected to the first oral glucose tolerance test (OGTT) and the first intraperitoneal insulin tolerance test (IPITT) at 4 and 5 weeks after surgery, respectively. Thereafter, mice were subjected to the second OGTT and IPITT at 16 and 17 weeks after surgery, respectively. (B,C) Weekly (B) and (C) cumulative food intake over 18 weeks. (D) Representative photograph of mice placed on HFD 60 at 15 weeks after injection of AAV-CTL or AAV-NPGL. (E) Weight. (F) Weekly weight gain. Statistical analyses were performed using two-way repeated measures ANOVA followed by Bonferroni's test (B,E,F) or Student's $t$-test $(\mathbf{C})$. Each value represents the mean \pm standard error of the mean (AAV-CTL: $n=8$, AAV-NPGL: $n=8$; $^{*} p<0.05,{ }^{* *} p<0.01,{ }^{* * *} p<0.005$ ).

\subsection{Glucose Tolerance and Insulin Sensitivity}

To investigate the effects of $\mathrm{Npgl}$ overexpression on glucose tolerance in HFD 60-fed mice, we subjected them to the OGTT at 4 and 16 weeks after surgery. The first OGTT, at 4 weeks, demonstrated that $\mathrm{Npgl}$ overexpression did not affect the blood glucose and insulin levels at $0,15,30,60$, or $120 \mathrm{~min}$ after glucose administration, and the glucose area under the curve (AUC) remained above the baseline (Figure 2A-C). The second OGTT at 16 weeks found that $\mathrm{Npgl}$ overexpression had no effect on blood glucose levels or the glucose AUC; however, $\mathrm{Npgl}$ overexpression was associated with significantly increased blood insulin levels at 0, 30, and 120 min after glucose administration (Figure 2D-F).

In addition to performing the OGTT, we also evaluated the insulin sensitivity of Npgl-overexpressing mice by subjecting them to the IPITT at 5 and 17 weeks after surgery.

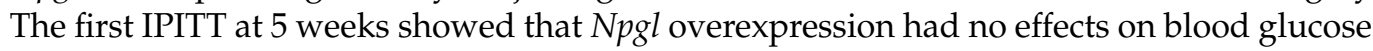
levels at $0,15,30,60$, and $120 \mathrm{~min}$ after intraperitoneal insulin administration, and the inverse AUC for glucose remained below the baseline (Figure 3A,B). Similarly, the second IPITT at 17 weeks found that $N p g l$ overexpression did not affect blood glucose levels or the inverse AUC for glucose (Figure 3C,D). 
A

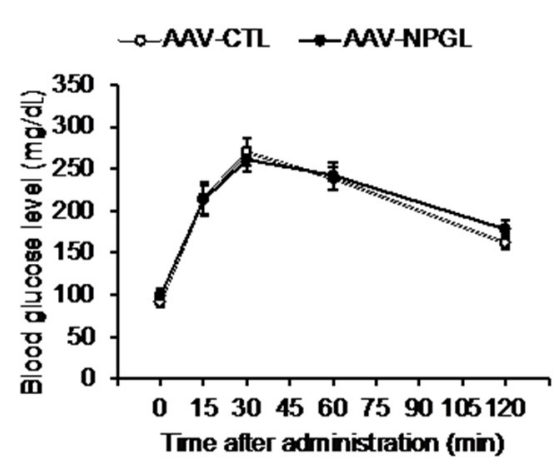

D

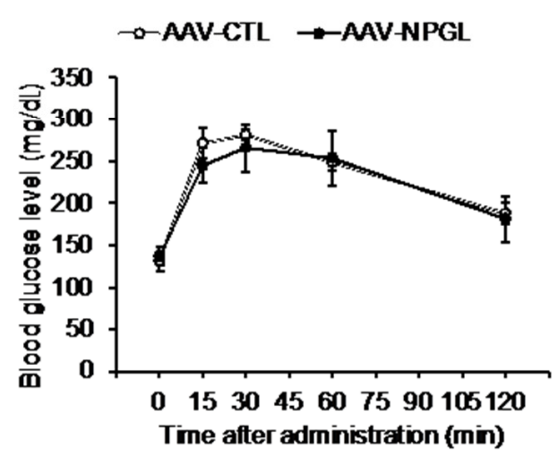

B

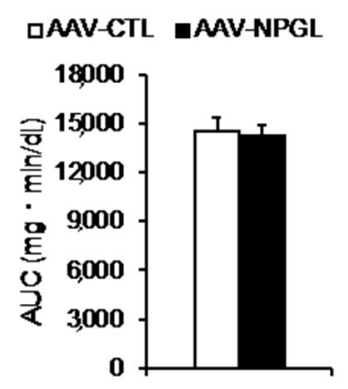

$\mathrm{E}$

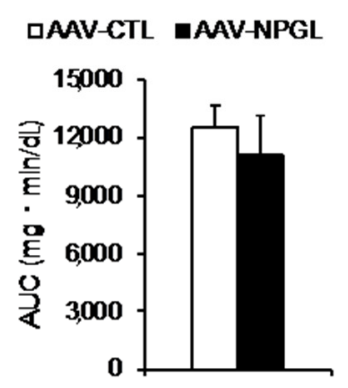

C

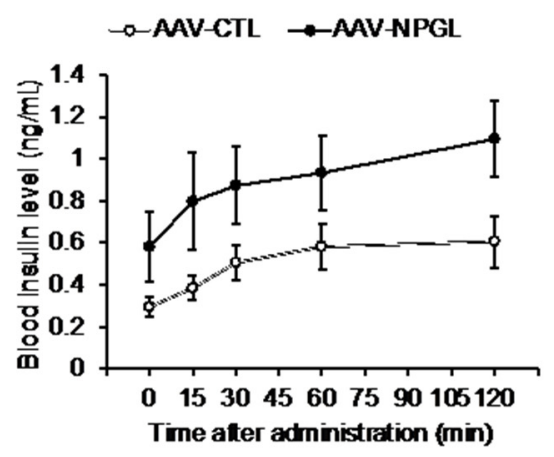

$\mathbf{F}$

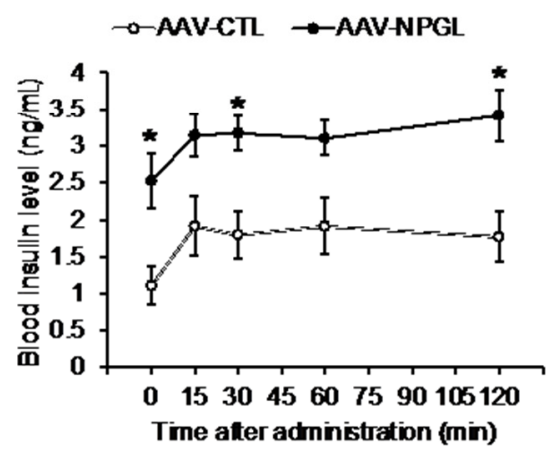

Figure 2. Effects of $\mathrm{Npgl}$ overexpression on glucose tolerance in mice fed a high-fat diet with 60\% calories from fat (HFD 60). These mice were injected with an adeno-associated virus (AAV) vector, either a control (AAV-CTL) or a vector carrying the NPGL precursor gene (AAV-NPGL). (A-F) Results of the oral glucose tolerance test (OGTT) at multiple time points in HFD 60-fed mice tested 4 weeks (A-C) and 16 weeks (D-F) after surgery. (A,D) Blood glucose levels. (B,E) Area under the curve (AUC) for blood glucose levels. (C,F) Corresponding blood insulin secretion curves. Statistical analyses were performed using two-way repeated measures ANOVA followed by Bonferroni's test (A,C,D,F) or Student's $t$-test (B,E). Each value represents the mean \pm standard error of the mean (AAV-CTL: $n=8$, AAV-NPGL: $n=8 ;{ }^{*} p<0.05$ ).

\subsection{Tissue and Organ Mass and Blood Biomarkers}

We next investigated the effects of an 18-week period of $\mathrm{Npgl}$ overexpression on tissue and organ mass. $\mathrm{Npgl}$ overexpression induced an increase in the mass of the perirenal WAT (pWAT) and a decrease in the mass of the epididymal WAT (eWAT), with visible changes in size (Figure 4A,B). However, $N p g l$ overexpression had little effect on the total WAT mass (Figure 4C). Concerning peripheral non-adipose tissues, $\mathrm{Npgl}$ overexpression increased the masses of the liver and kidney (Figure 4D), with visible hypertrophy of the liver (Figure 4E).

With regard to blood biomarkers, $\mathrm{Npgl}$ overexpression increased blood insulin levels but did not affect blood levels of glucose, leptin, triglycerides, or free fatty acids (Figure 5).

\section{4. mRNA Expression of Neuropeptide Genes and Genes Regulating Lipid Metabolism}

To illuminate the potential causes of our observations regarding increased food intake and changes in the mass of adipose and non-adipose tissues, we measured the mRNA expression levels of feeding-related neuropeptides in the $\mathrm{MBH}$, along with the mRNA expression of genes regulating lipid metabolism in the inguinal WAT (iWAT), eWAT, and liver. The following genes were analyzed: Npy and Agrp, encoding orexigenic factors as previously described; Pomc, encoding an anorexigenic factor as previously described; Acc (acetyl-CoA carboxylase), Fas (fatty acid synthase), Scd1 (stearoyl-CoA desaturase), and Gpat1 (glycerol-3-phosphate acyltransferase 1), encoding lipogenic enzymes; Chrebp $\alpha$ (carbohydrate-responsive element-binding protein $\alpha$ ), encoding a lipogenic transcription factor; Cpt1a (carnitine palmitoyltransferase 1a), Atgl (adipose triglyceride lipase), and 
Hsl (hormone-sensitive lipase), encoding lipolytic enzymes; Gapdh (glyceraldehyde-3phosphate dehydrogenase), encoding an enzyme involved in carbohydrate metabolism; Slc2a4 and Slc2a2 (solute carrier family 2 members 4 and 2), encoding glucose transporters;

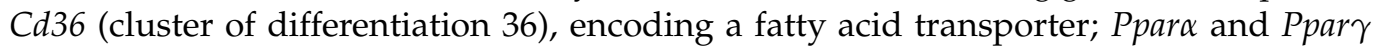
(peroxisome proliferator-activated receptor $\alpha$ and $\gamma$ ), encoding lipid-activated transcription factors; G6pase (glucose-6-phosphatase) and Pepck (phosphoenolpyruvate carboxykinase), encoding enzymes involved in gluconeogenesis and glucose uptake; and Fgf21 (fibroblast growth factor 21), encoding a metabolic hormone. Quantitative RT-PCR showed that Npgl overexpression was associated with increased Pomc mRNA expression in the MBH of HFD 60-fed mice (Figure S2). In the iWAT, Npgl overexpression did not affect any mRNA expression level (Figure 6A). In the eWAT, Npgl overexpression was associated with a significant decrease in Scd1 mRNA expression (Figure 6B). In the liver, Npgl overexpression was associated with a near-significant trend toward decreased Chrebp $\alpha$ mRNA expression (Figure 6C).

A

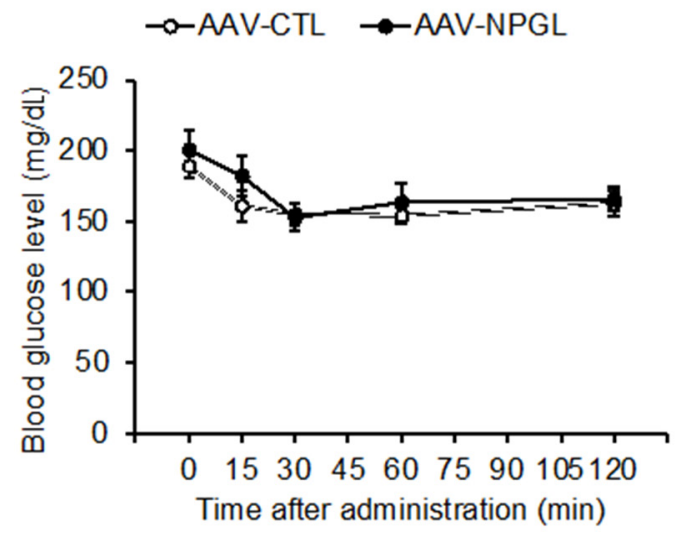

C

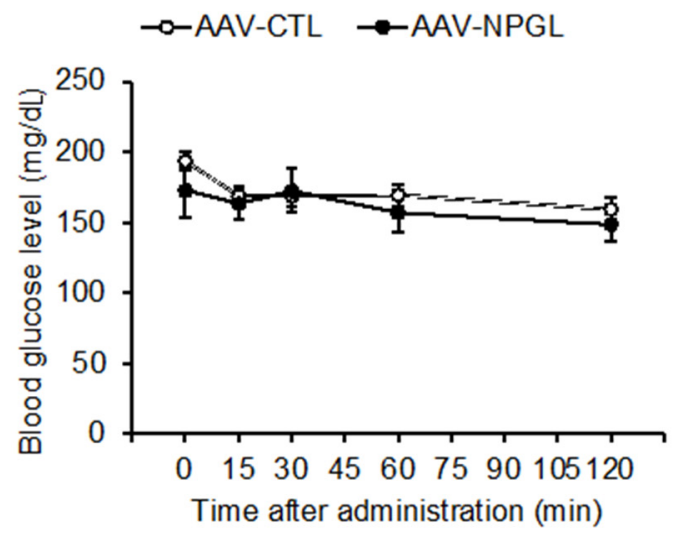

B 口AAV-CTL $\square A A V-N P G L$

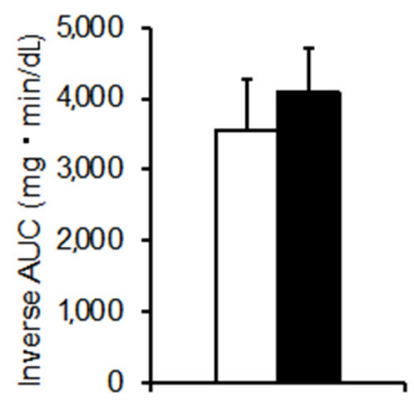

D

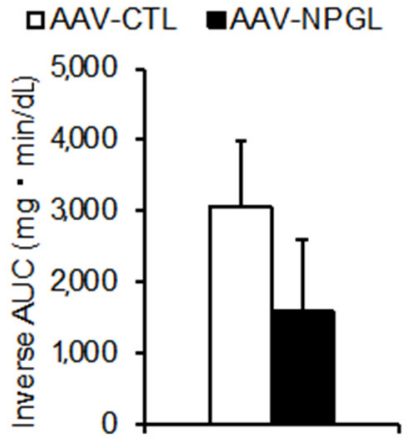

Figure 3. Effects of $\mathrm{Npgl}$ overexpression on insulin sensitivity in mice fed a high-fat diet with $60 \%$ calories from fat (HFD 60). These mice were injected with an adeno-associated virus (AAV) vector, either a control (AAV-CTL) or a vector carrying the NPGL precursor gene (AAV-NPGL). (A-D) Results of intraperitoneal insulin tolerance test (IPITT) at multiple time points in HFD 60-fed mice tested 5 weeks $(\mathbf{A}, \mathbf{B})$ and 17 weeks $(\mathbf{C}, \mathbf{D})$ after surgery. $(\mathbf{A}, \mathbf{C})$ Blood glucose levels. (B,D) Inverse area under the curve (AUC) for blood glucose levels. Statistical analyses were performed using two-way repeated measures ANOVA followed by Bonferroni's test $(\mathbf{A}, \mathbf{C})$ or Student's $t$-test $(\mathbf{B}, \mathbf{D})$. Each value represents the mean \pm standard error of the mean (AAV-CTL: $n=8$, AAV-NPGL: $n=8$ ). 
A

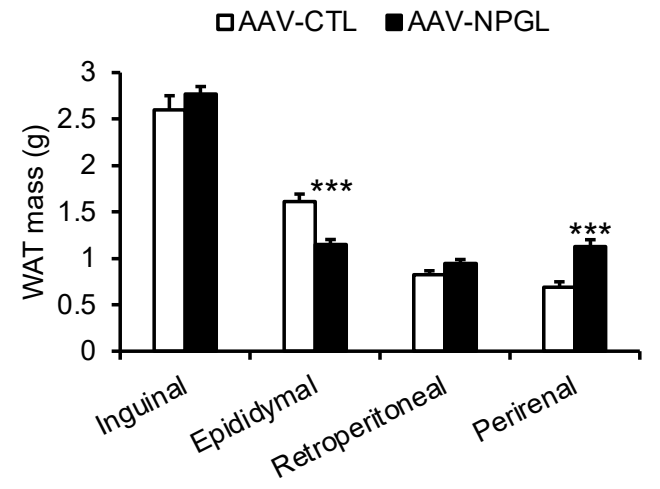

C

$\square A A V-C T L \quad \square A A V-N P G L$

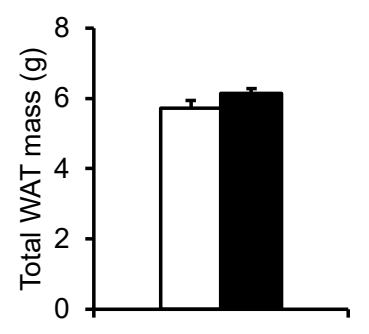

B

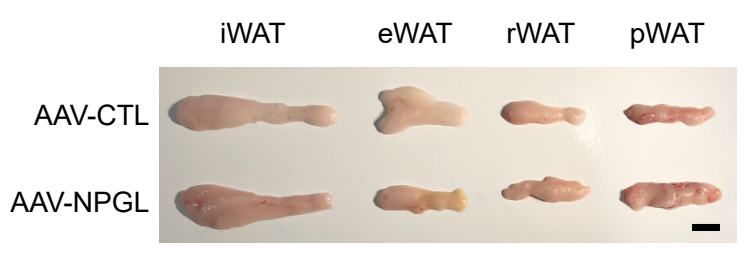

E
口AAV-CTL $\square$ AAV-NPGL

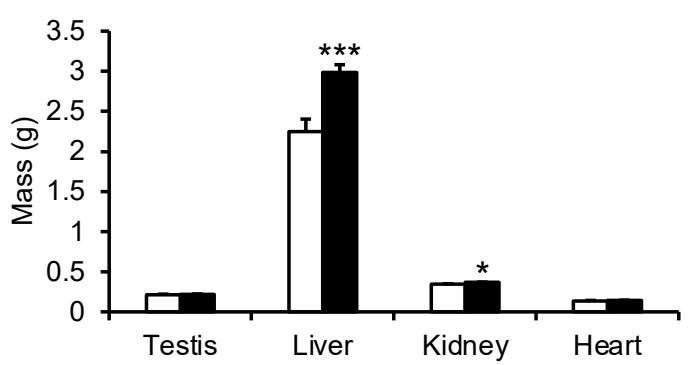

Liver

AAV-CTL

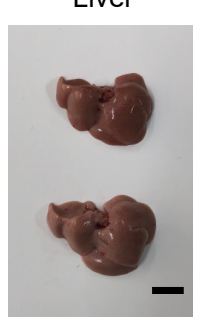

Figure 4. Effects of $\mathrm{Npgl}$ overexpression on tissue and organ mass in mice fed a high-fat diet with $60 \%$ calories from fat (HFD 60). These mice were injected with an adeno-associated virus (AAV) vector, either a control (AAV-CTL) or a vector carrying the NPGL precursor gene (AAV-NPGL). (A) Masses of the inguinal (i), epididymal (e), retroperitoneal (r), and perirenal (p) white adipose tissue (WAT). (B) Representative photographs of WAT from each region in HFD 60-fed mice at 18 weeks after injection of AAV-CTL or AAV-NPGL. (C) The total WAT mass. (D) Masses of the testes, liver, kidney, and heart. (E) Representative photograph of the liver in HFD 60-fed mice at 18 weeks after injection of AAV-CTL or AAV-NPGL. Scale bars $=1 \mathrm{~cm}$. All statistical analyses were performed using Student's $t$-test. Each value represents the mean \pm standard error of the mean (AAV-CTL: $n=8$, AAV-NPGL: $n=8$; $^{*} p<0.05,{ }^{* * *} p<0.005$ ).

A

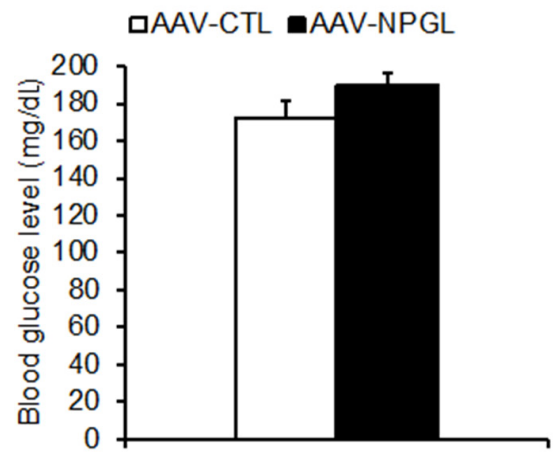

B

口AAV-CTL $\square A A V-N P G L$

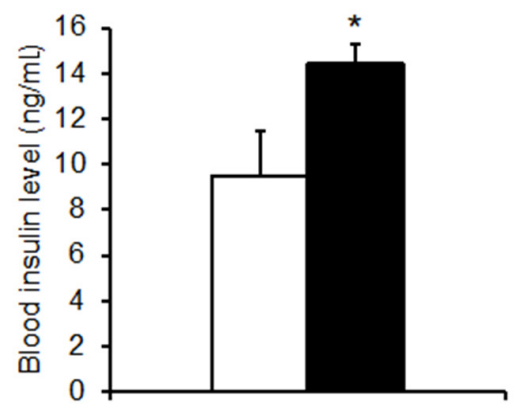

C

口AAV-CTL AAV-NPGL

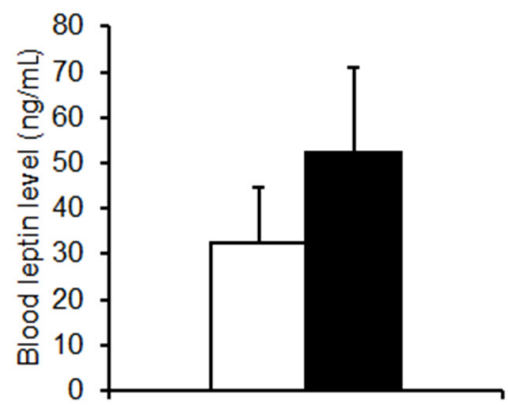

Figure 5. Cont. 
D

口AAV-CTL $=A A V-N P G L$

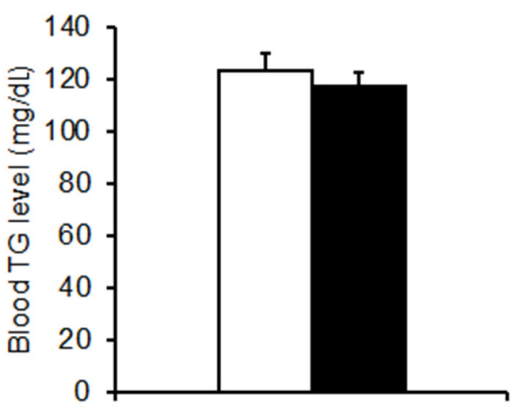

E

口AAV-CTL $=A A V-N P G L$

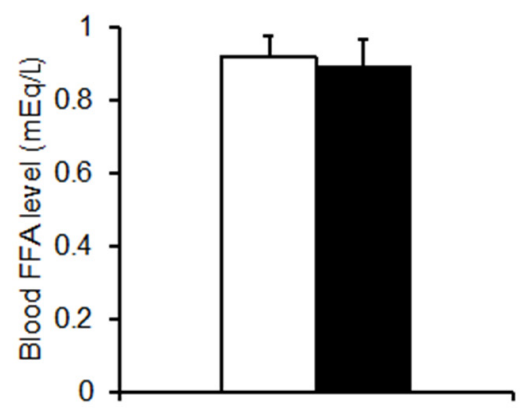

Figure 5. Effects of $\mathrm{Npgl}$ overexpression on blood biomarkers in mice fed a high-fat diet with $60 \%$ calories from fat. These mice were 26 weeks old at 18 weeks after injection of an adeno-associated virus (AAV) vector, either a control (AAV-CTL) or a vector carrying the NPGL precursor gene (AAV-NPGL). (A-E) Levels of blood glucose (A), insulin (B), leptin (C), triglycerides (TG) (D), and free fatty acids (FFA) (E). All statistical analyses were performed using Student's $t$-test. Each value represents the mean \pm standard error of the mean (AAV-CTL: $n=8$, AAV-NPGL: $n=8 ;^{*} p<0.05$ ).

A

iWAT

口AAV-CTL $=A A V-N P G L$

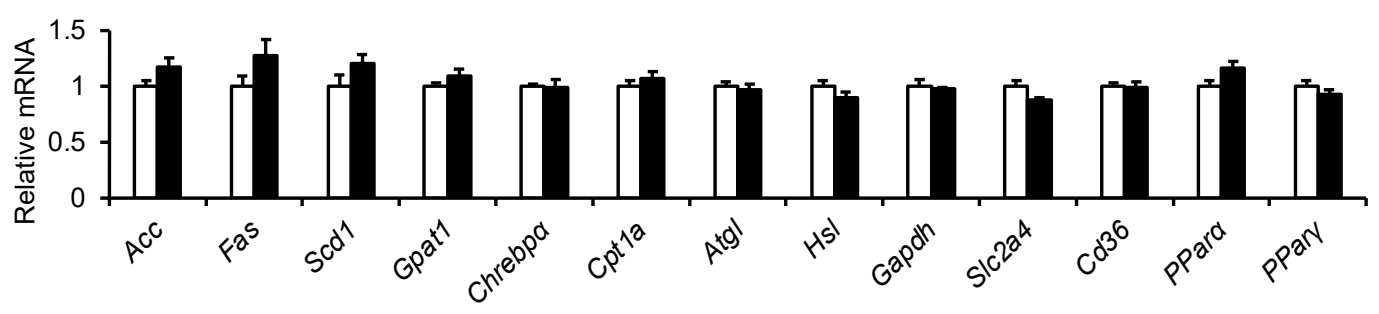

B

eWAT

$\square A A V-C T L \quad \square A A V-N P G L$

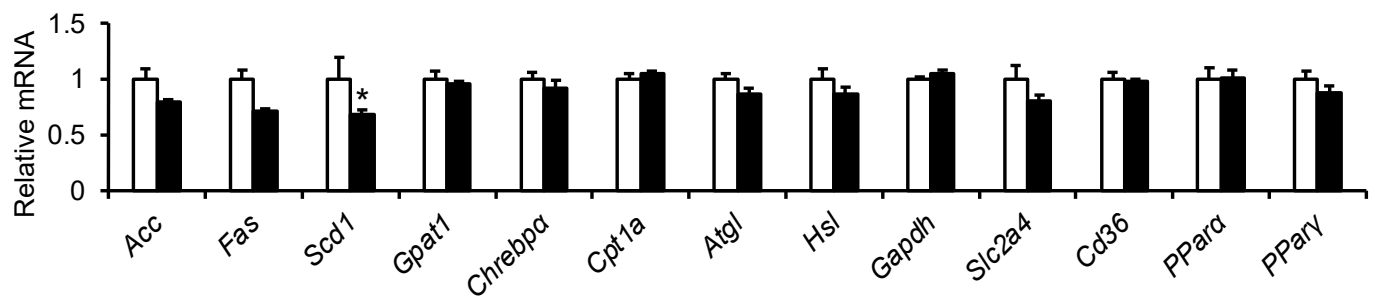

C Liver

口AAV-CTL $\square$ AAV-NPGL

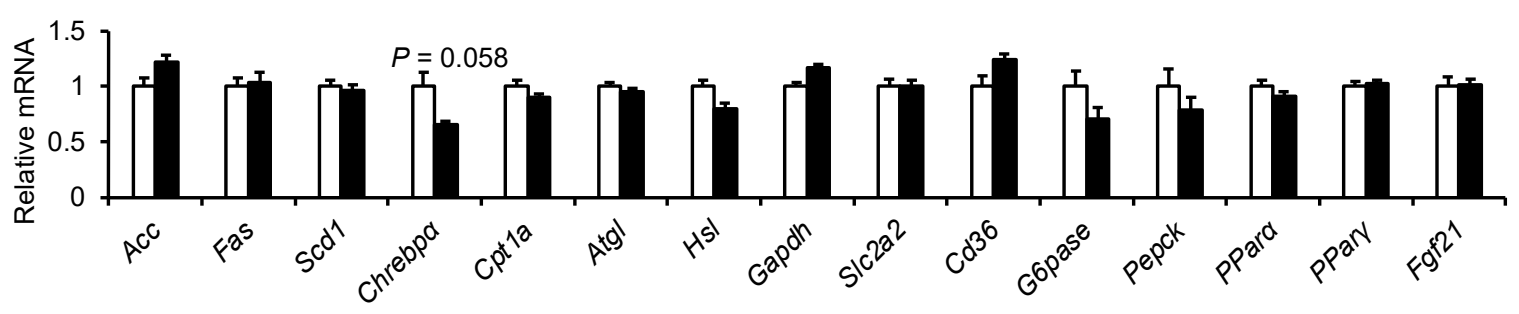

Figure 6. Effects of $\mathrm{Npgl}$ overexpression on mRNA expression of genes regulating lipid metabolism in mice fed a high-fat diet with $60 \%$ calories from fat. These mice were injected with an adeno-associated virus (AAV) vector, either a control (AAV-CTL) or a vector carrying the NPGL precursor gene (AAV-NPGL). (A-C) mRNA expression levels in the (A) inguinal white adipose tissue (iWAT), (B) epididymal white adipose tissue (eWAT), and (C) liver. All statistical analyses were performed using two-way ANOVA followed by Bonferroni's test. Each value represents the mean \pm standard error of the mean (AAV-CTL: $n=8$, AAV-NPGL: $n=8$; ${ }^{*}<0.05$ ). 


\section{Discussion}

Neuropeptides play crucial roles in the development of obesity through their effects on feeding behavior, metabolism, and fat accumulation [29,30]. In our previous work, we identified NPGL, a novel small secretory protein of the hypothalamus that stimulates feeding behavior and fat accumulation in rodents [22,23,26-28]. In one of our recent studies, we fed mice with normal chow for one month, then with an HFD ( $45 \%$ calories from fat) for another month; we found that $\mathrm{Npgl}$ overexpression was not associated with increased fat accumulation at the experimental endpoint, but it was associated with improvements in insulin resistance and glucose homeostasis [28]. These results suggest that NPGL may play multiple roles beyond regulating fat accumulation and has little effect on fat accumulation under HFD conditions. However, the effects of NPGL on feeding behavior and energy metabolism during long-term HFD feeding have previously remained unknown. In this study, $\mathrm{Npgl}$ overexpression in mice fed on an HFD 60 regimen was associated with decreased eWAT mass, an increased rate of weight gain for 7 weeks after induction of overexpression, and increased feeding behavior throughout the experimental period. Moreover, the OGTT and IPITT showed that $\mathrm{Npgl}$ overexpression maintained insulin sensitivity and glucose tolerance.

In this study, Npgl overexpression was not associated with increases in the masses of the iWAT or retroperitoneal WAT (rWAT) under HFD 60 feeding. Previous studies have suggested that in rodents, NPGL promotes fat accumulation in the WAT through de novo lipogenesis using dietary carbohydrates [23,26-28]. Indeed, we recently found that NPGL promotes fat accumulation in the WAT of rats fed a high-sucrose diet, even without increased food intake [27]. It is well-known that in rodents, dietary carbohydrates and fat execute opposite effects on de novo lipogenesis via a negative feedback loop [31,32]. For instance, ChREBP, a lipogenic transcription factor, is activated by dietary carbohydrates and promotes de novo lipogenesis, whereas dietary fat inhibits ChREBP activity [33,34]. Therefore, we speculate that increased levels of dietary fat may perturb NPGL-induced fat accumulation in the iWAT and rWAT, which occurs partially via de novo lipogenesis induced by transcription factors such as ChREBP. The present study also found that $\mathrm{Npgl}$ overexpression was associated with decreased eWAT mass and increased pWAT mass under HFD 60 feeding. Npgl overexpression suppressed the transcription level of $S c d 1$, a lipogenic gene, in the eWAT; this may have caused the decrease in eWAT mass. Several previous studies have found that each region of WAT seems to be innervated by different central neural circuits [35-39]. In addition, one of our previous studies found that NPGL inhibits the activity of sympathetic nerves, perhaps contributing to fat accumulation (unpublished data). Future studies of the detailed mechanisms of NPGL action in sympathetic nerves will help clarify the different processes of fat accumulation in each region of WAT.

In this study, Npgl overexpression was associated with increased feeding behavior under HFD 60 feeding. Most of our previous studies have found an orexigenic effect for NPGL, but a few studies have found that NPGL induces no increase in food intake under HFD conditions $[27,28]$. Considerable research exists to support the notion that dietary nutrients influence the mechanisms by which neuropeptides regulate feeding behavior $[40,41]$. For instance, long-term HFD feeding evokes neuronal activation in NPY / AgRP neurons via peripheral signaling in mice [42]. While the effects of dietary nutrients on NPGL action remain unclear, we have already found that NPGL-like immunoreactive fibers contact the anorexigenic POMC neurons in the arcuate nucleus of mice [22]. In the present study, $\mathrm{Npgl}$ overexpression influenced POMC at the transcriptional level. In our previous studies, NPGL appeared to induce food intake, subsequent weight gain, and storage of digested nutrients as fat reserves (mainly in the WAT) [23,26-28]. However, in the present study,

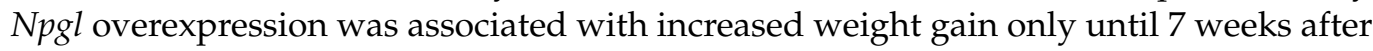
surgery, even though it was associated with increased food intake throughout the course of the study. Therefore, we hypothesize that under long-term HFD 60 feeding, NPGL suppresses fat accumulation in certain regions of WAT, such as the eWAT, to prevent excessive weight gain and obesity. Nevertheless, $\mathrm{Npgl}$ overexpression was associated with increased 
liver mass with visible hypertrophy. This increase in mass was likely due to storage of digested nutrients in the liver and/or other peripheral tissues under long-term HFD 60 feeding, which also resulted in increased weight. However, the liver transcript level of Chrebpa, which encodes a lipogenic transcription factor, tended to be reduced by $\mathrm{Npgl}$ overexpression, implying a negative feedback loop caused by fat accumulation in the liver.

The OGTT showed that although $\mathrm{Npgl}$ overexpression was associated with increased food intake and liver hypertrophy, it was not associated with glucose intolerance. Many studies have demonstrated that HFD-induced fat accumulation in peripheral tissues tends to be accompanied by chronic inflammation, leading to metabolic disturbances such as glucose intolerance [43,44]. For instance, hepatic steatosis stimulates inflammatory signaling pathways in the liver, contributing to glucose intolerance and insulin resistance [45]. In addition, a previous study found that sympathetic nerve deactivation induced by hypothalamic AgRP causes inflammation in the eWAT [46]. Therefore, it is likely that NPGL helps maintain a normal metabolic state not only by regulating fat accumulation but also by reducing chronic inflammation in peripheral tissues. However, we observed increased blood insulin levels in Npgl-overexpressing mice during the OGTT at 16 weeks and at the experimental endpoint. To date, several peripheral factors have been identified as incretins [47]. For instance, glucagon-like peptide-1, a 31-amino-acid hormone secreted from the lower intestine and colon, acts directly on the pancreatic islets to stimulate insulin secretion $[48,49]$. In this study, the IPITT showed that Npgl-overexpressing mice did not display insulin resistance despite their hyperinsulinemia. These results suggest that NPGL may increase blood insulin levels by activating incretins and by stimulating fat accumulation in peripheral tissues such as the liver.

Although the present study addressed a novel function of NPGL, i.e., suppressing fat accumulation in the eWAT of mice exposed to long-term HFD 60 feeding, there still remain

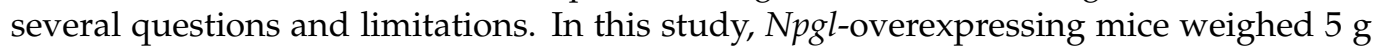
more than the control animals, even though they did not show differences in the total WAT mass. A previous study has shown that HFD affects systemic metabolism and the size of several peripheral tissues, such as the intestine [50]. Therefore, further studies on other tissues are required to address the physiological changes induced by NPGL. Moreover, a recent study has demonstrated that there are sex differences in obesity development of mice [51]. However, we reported that $\mathrm{Npgl}$ overexpression affected food intake and fat accumulation only in male mice. It is required to conduct subsequent analysis using female mice to explore the function of NPGL in both sexes. Furthermore, we could not address locomotor activity in Npgl-overexpressing mice under HFD 60 feeding in the present study. On the other hand, our previous study has shown that Npgl overexpression does not affect the locomotor activity of NC-fed mice [52]. Further studies using various diets will uncover the effects of NPGL on physiological activity and metabolic state under different nutritional conditions.

In summary, the present study revealed that $\mathrm{Npgl}$ overexpression had little effect on total WAT mass under long-term HFD 60 feeding, although it appeared to increase food intake. However, $\mathrm{Npgl}$ overexpression appeared to have opposing effects on fat accumulation in the WAT, being associated with increased pWAT mass but decreased eWAT mass. Given these results, we speculate that under conditions of diet-induced obesity, such as that induced by long-term HFD 60 feeding, NPGL may play roles both in accelerating energy storage and in suppressing excess fat accumulation in certain tissues, such as the eWAT. It is hoped that further research will open up new avenues for the therapeutic application of NPGL as a way to prevent obesity.

\section{Materials and Methods}

\subsection{Animals}

Male C57BL/6J mice (5 weeks old) were purchased from Japan SLC (Hamamatsu, Japan) and housed under standard conditions $\left(25 \pm 1{ }^{\circ} \mathrm{C}\right.$ under a 12 -h light/dark cycle) with ad libitum access to water. The mice were placed on an HFD $(60 \%$ of calories from 
fat, $7.1 \%$ of calories from sucrose; D12492, Research Diets, New Brunswick, NJ, USA). To induce $\mathrm{Npgl}$ overexpression, animals were subjected to stereotaxic surgery under isoflurane anesthesia. Sixteen animals were randomly divided into two groups of eight animals each and used for the control and Npgl overexpression groups. All individuals were applied to the statistical tests.

\subsection{Production of $A A V$-Based Vectors}

AAV-based vectors were produced following a previously reported method [23]. Briefly, the full-length open reading frame of mouse $N p g l$ was amplified from cDNA of the mediobasal hypothalamus and inserted into the pAAV-IRES-GFP expression vector including the sequence of cytomegalovirus (CMV) promoter (Cell Biolabs, San Diego, CA, USA). The primers for mouse $N p g l$ were $5^{\prime}$-CGATCGATACCATGGCTGATCCTGGGC-3' (sense) and 5'-CGGAATTCTTATTTTCTCTTTACTTCCAGC-3' (antisense). AAV-based vectors AAV-DJ/8-NPGL-IRES-GFP for NPGL (AAV-NPGL) and AAV-DJ/8-IRES-GFP for the control (AAV-CTL) were produced in 293AAV cells (Cat\# AAV-100; Cell Biolabs) using the AAV-DJ/8 Helper Free Packaging System containing pAAV-DJ /8 and pHelper plasmids (Cell Biolabs). The AAV-based vectors were prepared at a concentration of $1 \times 10^{9}$ particles $/ \mu \mathrm{L}$ and stored at $-80^{\circ} \mathrm{C}$ until use.

\subsection{Stereotaxic Surgery}

To induce $N p g l$ overexpression, mice were bilaterally injected with $0.5 \mu \mathrm{L} / \mathrm{site}$ $\left(5.0 \times 10^{8}\right.$ particles/site) of AAV-based vectors that either carried the $N p g l$ gene $(\mathrm{AAV}$ NPGL) or served as controls (AAV-CTL). Vectors were injected into the MBH region (2.2 $\mathrm{mm}$ caudal to the bregma, $0.25 \mathrm{~mm}$ lateral to the midline, and $5.8 \mathrm{~mm}$ ventral to the skull surface) using a Neuros Syringe (7001 KH; Hamilton, Reno, NV, USA). Npgl overexpression was maintained throughout the course of the study and confirmed by quantitative RT-PCR at the experimental endpoint. Food intake and weight were measured weekly (9:00 a.m.). At the experimental endpoint, mice were immediately decapitated, and tissue and organ mass were assessed. Blood samples were collected at sacrifice.

\subsection{OGTT and IPITT}

The OGTT and IPITT were performed at weekly intervals following a previously reported method [53]. Briefly, mice were fasted for $16 \mathrm{~h}$ (overnight fasting) for the OGTT and $4 \mathrm{~h}$ (morning fasting) for the IPITT. Using a GLUCOCARD G+ blood glucose meter (Arkray, Kyoto, Japan), blood glucose levels were measured at 0, 15, 30, 60, and 120 min after oral glucose administration for the OGTT $(1 \mathrm{~g} / \mathrm{kg}$ weight $)$ and intraperitoneal insulin injection for the IPITT $(0.75$ units $/ \mathrm{kg})$. A $35-\mu \mathrm{L}$ blood sample was collected from the tail vein using a heparinized plastic hematocrit tube (Drummond Scientific Company, Broomall, PA, USA), and the plasma was separated by centrifugation at $2500 \times g$ for $30 \mathrm{~min}$. After centrifugation, the plasma was stored at $-80^{\circ} \mathrm{C}$ for insulin measurement. A LBIS Insulin-Mouse-U ELISA kit (Shibayagi, Gunma, Japan) was used to measure insulin levels. The AUC and inverse AUC for blood glucose were calculated by the linear trapezoidal method for both the OGTT and the IPITT.

\subsection{Quantitative RT-PCR}

The MBH was dissected out using fine forceps and small scissors with reference to a mouse brain atlas [54], then snap-frozen in liquid nitrogen for RNA processing. The extracted regions included the supraoptic nucleus, dorsomedial hypothalamus, ventromedial hypothalamus, arcuate nucleus, lateral hypothalamic area, and mammillary nucleus. Total RNA was extracted using TRIzol reagent (Life Technologies, Carlsbad, CA, USA; $\mathrm{MBH}$ and liver) or QIAzol lysis reagent (QIAGEN, Venlo, The Netherlands; iWAT and eWAT) in accordance with the manufacturers' instructions. First-strand cDNA was synthesized from total RNA using a PrimeScript RT Reagent Kit with gDNA Eraser (Takara Bio, Shiga, Japan). 
The primer sequences used in this study are listed in Table 1. The quantitative RT-PCR was conducted following previously reported methods $[23,26]$. Relative expression of each gene was determined by the $2^{-\Delta \Delta \mathrm{Ct}}$ method; the beta-actin gene $(A c t b)$ was used as an internal control for the $\mathrm{MBH}$ and liver, and the ribosomal protein S18 gene (Rps18) was used as an internal control for the iWAT and eWAT.

Table 1. Sequences of oligonucleotide primers for quantitative RT-PCR.

\begin{tabular}{|c|c|c|}
\hline Gene & Sense Primer $\left(5^{\prime}\right.$ to $\left.3^{\prime}\right)$ & Antisense Primer $\left(5^{\prime}\right.$ to $\left.3^{\prime}\right)$ \\
\hline$N p g l$ & TATGTAGACTGTGTCCTCTC & TCTAAGGAGCTGAGAATATGCA \\
\hline Npy & TATCTCTGCTCGTGTGTTTG & GATTGATGTAGTGTCGCAGA \\
\hline Agrp & TGTTCCCAGAGTTCCCAGGTC & GCATTGAAGAAGCGGCAGTAGCAC \\
\hline Pomc & AGCTGCCTTTCCGCGACA & ATCTATGGAGGTCTGAAGCA \\
\hline$A c c$ & TCCGCACTGACTGTAACCACAT & TGCTCCGCACAGATTCTTCA \\
\hline Fas & AGGGGTCGACCTGGTCCTCA & GCCATGCCCAGAGGGTGGTT \\
\hline Scd1 & CTGTACGGGATCATACTGGTTC & GCCGTGCCTTGTAAGTTCTG \\
\hline Gpat1 & TCATCCAGTATGGCATTCTCACA & GCAAGGCCAGGACTGACATC \\
\hline Chrebpo & CGACACTCACССАССТСТTC & TTGTTCAGCCGGATCTTGTC \\
\hline Cpt1a & CCTGGGCATGATTGCAAAG & GGACGCCACTCACGATGTT \\
\hline Atgl & AACACCAGCATCCAGTTCAA & GGTTCAGTAGGCCATTCCTC \\
\hline Hsl & GCTGGGCTGTCAAGCACTGT & GTAACTGGGTAGGCTGCCAT \\
\hline Gapdh & AAGGTCATCCCAGAGCTGAA & CTGCTTCACCACCTTCTTGA \\
\hline Slc2a4 & GTAACTTCATTGTCGGCATGG & AGCTGAGATCTGGTCAAACG \\
\hline Cd36 & TCCTCTGACATTTGCAGGTCTATC & AAAGGCATTGGCTGGAAGAA \\
\hline Ppard & TCGAATATGTGGGGACAAGG & GACAGGCACTTGTGAAAACG \\
\hline Ppary & GCCCTTTGGTGACTTTATGGA & GCAGCAGGTTGTCTTGGATG \\
\hline G6pase & ACTGTGGGCATCAATCTCCTC & CGGGACAGACAGACGTTCAGC \\
\hline Pepck & GTGCTGGAGTGGATGTTCGG & CTGGCTGATTCTCTGTTTCAGG \\
\hline Slc2a2 & GGCTAATTTCAGGACTGGTT & TTTCTTTGCССTGACTTCСT \\
\hline$F g f 21$ & СCTCTAGGTTTCTTTGCCAACAG & AAGCTGCAGGCCTCAGGAT \\
\hline Actb & GGCACCACACCTTCTACAAT & AGGTCTCAAACATGATCTGG \\
\hline Rps18 & CCTGAGAAGTTCCAGCACAT & TTCTCCAGCCCTCTTGGTG \\
\hline
\end{tabular}

\subsection{Blood Biomarker Analysis}

Blood levels of glucose, lipids, and insulin at the experimental endpoint were measured using appropriate equipment, reagents, and kits. The GLUCOCARD G+ blood glucose meter (Arkray) was used to measure the glucose content. The LBIS Insulin-MouseT ELISA kit (Shibayagi) was used to measure the insulin levels. The leptin ELISA Kit (Morinaga Institute of Biological Science, Yokohama, Japan) was used to measure leptin levels. The Triglyceride E-Test Wako (Wako Pure Chemical Industries, Osaka, Japan) was used to measure the triglyceride levels. The NEFA C-Test Wako (Wako Pure Chemical Industries) was used to measure the free fatty acid levels.

\subsection{Statistical Analysis}

Data were analyzed using Student's $t$-test (Figures 1C; $2 B, E ; 3 B, D ; 4 A, C, D ; 5 A-E$; S1), two-way repeated measures ANOVA followed by Bonferroni's test (Figures 1B,E,F; 2A,C,D,F; 3A,C), or two-way ANOVA followed by Bonferroni's test (Figures 6A-C; S2) as indicated in the respective figures. $p$ values $<0.05$ were considered significant. 
Supplementary Materials: Figure S1: Intensity of Npgl overexpression at the experimental endpoint in the mediobasal hypothalamus of mice fed a high-fat diet $(60 \%$ calories from fat). These mice were injected with an adeno-associated virus (AAV) vector, either a con-trol (AAV-CTL) or a vector carrying the NPGL precursor gene (AAV-NPGL). The panel compares the levels of mRNA expression of Npgl between the AAV-CTL and AAV-NPGL groups. Statistical analysis was performed using Student's $t$-test. Each value represents the mean \pm standard error of the mean (AAV-CTL: $n=8$, AAV-NPGL: $\left.n=8 ;{ }^{* * *} p<0.005\right)$. Figure S2: Effects of Npgl overexpression on mRNA expression of neuropeptides (Npy, neuropeptide Y; Agrp, agouti-related peptide) and a neuropeptide precursor (Pomc; proopiomelanocortin) in the mediobasal hypothalamus of mice fed a high-fat diet $(60 \%$ calories from fat). These mice were injected with an adeno-associated virus (AAV) vector, either a control (AAV-CTL) or a vector carrying the NPGL precursor gene (AAV-NPGL). The panel compares the levels of mRNA expression of Npy, Agrp, and Pomc between the AAV-CTL and AAV-NPGL groups. Statistical analysis was performed using two-way ANOVA followed by Bonferroni's test. Each value represents the mean \pm standard error of the mean (AAV-CTL: $n=8$, AAV-NPGL: $n=8$; ** $p<0.01)$.

Author Contributions: Conceptualization, K.F. and K.U.; methodology, K.F., Y.N., S.M., E.I-U. and M.F.; investigation, K.F., Y.N., S.M., E.I-U., M.F. and K.U.; writing-original draft preparation, K.F.; writing - review and editing, K.F. and K.U.; visualization, K.F.; project administration, K.U.; funding acquisition, K.F., E.I.-U. and K.U. All authors have read and agreed to the published version of the manuscript.

Funding: This work was supported by JSPS KAKENHI Grant (JP20K22741 to K.F., JP19K06768 to E.I.-U., and JP19H03258 to K.U.), the Takeda Science Foundation (K.U.), the Uehara Memorial Foundation (K.U.), and the Ono Medical Research Foundation (K.U.).

Institutional Review Board Statement: All animal experiments were performed according to the Guide for the Care and Use of Laboratory Animals prepared by Hiroshima University (HigashiHiroshima, Japan), and these procedures were approved by the Institutional Animal Care and Use Committee of Hiroshima University (permit numbers: 30-92-2, 4 June 2019; and C19-8, 30 August 2019).

Informed Consent Statement: Not applicable.

Data Availability Statement: No big data repositories needed. The raw data supporting the findings of this manuscript will be made available by the corresponding authors, K.F. and K.U., to any qualified researchers upon reasonable request.

Acknowledgments: We are grateful to Atsuki Kadota (Hiroshima University) for the experimental support.

Conflicts of Interest: The authors declare no conflict of interest.

Sample Availability: Not applicable.

\section{References}

1. Haslam, D.W.; James, W.P.T. Obesity. Lancet 2005, 366, 1197-1209. [CrossRef]

2. Hruby, A.; Hu, F.B. The epidemiology of obesity: A big picture. Pharmacoeconomics 2015, 33, 673-689. [CrossRef] [PubMed]

3. Ghosh, S.; Bouchard, C. Convergence between biological, behavioural and genetic determinants of obesity. Nat. Rev. Genet. 2017, 18, 731-748. [CrossRef] [PubMed]

4. Stolarczyk, E. Adipose tissue inflammation in obesity: A metabolic or immune response? Curr. Opin. Pharmacol. 2017, 37, 35-40. [CrossRef] [PubMed]

5. Olefsky, J.M.; Glass, C.K. Macrophages, inflammation, and insulin resistance. Annu. Rev. Physiol. 2010, 72, 219-246. [CrossRef] [PubMed]

6. Schwartz, M.W.; Porte, D. Diabetes, obesity, and the brain. Science 2005, 307, 375-379. [CrossRef] [PubMed]

7. Morton, G.J.; Cummings, D.E.; Baskin, D.G.; Barsh, G.S.; Schwartz, M.W. Central nervous system control of food intake and body weight. Nature 2006, 443, 289-295. [CrossRef] [PubMed]

8. Morton, G.J.; Meek, T.H.; Schwartz, M.W. Neurobiology of food intake in health and disease. Nat. Rev. Neurosci. 2014, 15, 367-378. [CrossRef] [PubMed]

9. Macia, L.; Yulyaningsih, E.; Pangon, L.; Nguyen, A.D.; Lin, S.; Shi, Y.C.; Zhang, L.; Bijker, M.; Grey, S.; Mackay, F.; et al. Neuropeptide Y1 receptor in immune cells regulates inflammation and insulin resistance associated with diet-induced obesity. Diabetes 2012, 61, 3228-3238. [CrossRef] 
10. Kamegai, J.; Tamura, H.; Shimizu, T.; Ishii, S.; Sugihara, H.; Wakabayashi, I. Chronic central infusion of ghrelin increases hypothalamic neuropeptide $\mathrm{Y}$ and agouti-related protein mRNA levels and body weight in rats. Diabetes 2001, 51, 2438-2443. [CrossRef]

11. Nakazato, M.; Murakami, N.; Date, Y.; Kojima, M.; Matsuo, H.; Kangawa, K.; Matsukura, S. A role for ghrelin in the central regulation of feeding. Nature 2001, 409, 194-198. [CrossRef]

12. Cowley, M.A.; Smith, R.G.; Diano, S.; Tschöp, M.; Pronchuk, N.; Grove, K.L.; Strasburger, C.J.; Bidlingmaier, M.; Esterman, M.; Heiman, M.L.; et al. The distribution and mechanism of action of ghrelin in the CNS demonstrates a novel hypothalamic circuit regulating energy homeostasis. Neuron 2003, 37, 649-661. [CrossRef]

13. Cowley, M.A.; Smart, J.L.; Rubinstein, M.; Cerdán, M.G.; Diano, S.; Horvath, T.L.; Cone, R.D.; Low, M.J. Leptin activates anorexigenic POMC neurons through a neural network in the arcuate nucleus. Nature 2001, 411, 480-484. [CrossRef]

14. Vong, L.; Ye, C.; Yang, Z.; Choi, B.; Chua, S.; Lowell, B.B. Leptin action on GABAergic neurons prevents obesity and reduces inhibitory tone to POMC neurons. Neuron 2011, 71, 143-154. [CrossRef]

15. Zhang, Y.; Proenca, R.; Maffei, M.; Barone, M.; Leopold, L.; Friedman, J.M. Positional cloning of the mouse obese gene and its human homologue. Nature 1994, 372, 425-432. [CrossRef]

16. Amitani, M.; Asakawa, A.; Amitani, H.; Inui, A. The role of leptin in the control of insulin-glucose axis. Front. Neurosci. 2013, 7, 7. [CrossRef] [PubMed]

17. Castañeda, T.R.; Tong, J.; Datta, R.; Culler, M.; Tschöp, M.H. Ghrelin in the regulation of body weight and metabolism. Front. Neuroendocrinol. 2010, 31, 44-60. [CrossRef] [PubMed]

18. Koch, L.; Wunderlich, F.T.; Seibler, J.; Könner, A.C.; Hampel, B.; Irlenbusch, S.; Brabant, G.; Kahn, C.R.; Schwenk, F.; Brüning, J.C. Central insulin action regulates peripheral glucose and fat metabolism in mice. J. Clin. Investig. 2008, 118, 2132-2147. [CrossRef] [PubMed]

19. Petersen, M.C.; Shulman, G.I. Mechanisms of insulin action and insulin resistance. Physiol. Rev. 2018, 98, 2133-2223. [CrossRef] [PubMed]

20. Ukena, K.; Iwakoshi-Ukena, E.; Taniuchi, S.; Bessho, Y.; Maejima, S.; Masuda, K.; Shikano, K.; Kondo, K.; Furumitsu, M.; Tachibana, T. Identification of a cDNA encoding a novel small secretory protein, neurosecretory protein GL, in the chicken hypothalamic infundibulum. Biochem. Biophys. Res. Commun. 2014, 446, 298-303. [CrossRef]

21. Ukena, K. Avian and murine neurosecretory protein GL participates in the regulation of feeding and energy metabolism. Gen. Comp. Endocrinol. 2018, 260, 164-170. [CrossRef]

22. Matsuura, D.; Shikano, K.; Saito, T.; Iwakoshi-Ukena, E.; Furumitsu, M.; Ochi, Y.; Sato, M.; Bentley, G.E.; Kriegsfeld, L.J.; Ukena, K. Neurosecretory protein GL, a hypothalamic small secretory protein, participates in energy homeostasis in male mice. Endocrinology 2017, 158, 1120-1129. [CrossRef]

23. Iwakoshi-Ukena, E.; Shikano, K.; Kondo, K.; Taniuchi, S.; Furumitsu, M.; Ochi, Y.; Sasaki, T.; Okamoto, S.; Bentley, G.E.; Kriegsfeld, L.J.; et al. Neurosecretory protein GL stimulates food intake, de novo lipogenesis, and onset of obesity. eLife 2017, 6, e28527. [CrossRef]

24. Shikano, K.; Kato, M.; Iwakoshi-Ukena, E.; Furumitsu, M.; Matsuura, D.; Masuda, K.; Tachibana, T.; Bentley, G.E.; Kriegsfeld, L.J.; Ukena, K. Effects of chronic intracerebroventricular infusion of neurosecretory protein GL on body mass and food and water intake in chicks. Gen. Comp. Endocrinol. 2018, 256, 37-42. [CrossRef]

25. Shikano, K.; Iwakoshi-Ukena, E.; Kato, M.; Furumitsu, M.; Bentley, G.E.; Kriegsfeld, L.J.; Ukena, K. Neurosecretory protein GL induces fat accumulation in chicks. Front. Endocrinol. 2019, 10, 392. [CrossRef]

26. Shikano, K.; Iwakoshi-Ukena, E.; Saito, T.; Narimatsu, Y.; Kadota, A.; Furumitsu, M.; Bentley, G.E.; Kriegsfeld, L.J.; Ukena, K. Neurosecretory protein GL induces fat accumulation in mice. J. Endocrinol. 2020, 244, 1-12. [CrossRef]

27. Fukumura, K.; Shikano, K.; Narimatsu, Y.; Iwakoshi-Ukena, E.; Furumitsu, M.; Naito, M.; Ukena, K. Effects of neurosecretory protein GL on food intake and fat accumulation under different dietary nutrient compositions in rats. Biosci. Biotechnol. Biochem. 2021, 85, 1513-1520. [CrossRef]

28. Fukumura, K.; Narimatsu, Y.; Moriwaki, S.; Iwakoshi-Ukena, E.; Furumitsu, M.; Ukena, K. Effects of overexpression of neurosecretory protein GL-precursor gene on glucose homeostasis and insulin sensitivity in mice. Int. J. Mol. Sci. 2021, $22,4681$. [CrossRef] [PubMed]

29. Berthoud, H.R.; Morrison, C. The brain, appetite, and obesity. Annu. Rev. Psychol. 2008, 59, 55-92. [CrossRef] [PubMed]

30. Andermann, M.L.; Lowell, B.B. Toward a wiring diagram understanding of appetite control. Neuron 2017, 95, 757-778. [CrossRef] [PubMed]

31. Delgado, T.C.; Pinheiro, D.; Caldeira, M.; Castro, M.M.; Geraldes, C.F.; López-Larrubia, P.; Cerdán, S.; Jones, J.G. Sources of hepatic triglyceride accumulation during high-fat feeding in the healthy rat. NMR Biomed. 2009, 22, 310-317. [CrossRef]

32. Duarte, J.A.; Carvalho, F.; Pearson, M.; Horton, J.D.; Browning, J.D.; Jones, J.G.; Burgess, S.C. A high-fat diet suppresses de novo lipogenesis and desaturation but not elongation and triglyceride synthesis in mice. J. Lipid Res. 2014, 55, 2541-2553. [CrossRef]

33. Abdul-Wahed, A.; Guilmeau, S.; Postic, C. Sweet sixteenth for ChREBP: Established roles and future goals. Cell Metab. 2017, 26, 324-341. [CrossRef]

34. Dentin, R.; Benhamed, F.; Pégorier, J.P.; Foufelle, F.; Viollet, B.; Vaulont, S.; Girard, J.; Postic, C. Polyunsaturated fatty acids suppress glycolytic and lipogenic genes through the inhibition of ChREBP nuclear protein translocation. J. Clin. Investig. 2005, 115, 2843-2854. [CrossRef] 
35. Youngstrom, T.G.; Bartness, T.J. Catecholaminergic innervation of white adipose tissue in Siberian hamsters. Am. J. Physiol. Regul. Integr. Comp. Physiol. 1995, 268, 733-751. [CrossRef]

36. Bamshad, M.; Aoki, V.T.; Adkison, M.G.; Warren, W.S.; Bartness, T.J. Central nervous system origins of the sympathetic nervous system outflow to white adipose tissue. Am. J. Physiol. Regul. Integr. Comp. Physiol. 1998, 275, 291-299. [CrossRef] [PubMed]

37. Bartness, T.J.; Song, C.K. Brain-adipose tissue neural crosstalk. Physiol. Behav. 2007, 91, 343-351. [CrossRef] [PubMed]

38. Bartness, T.J.; Shrestha, Y.B.; Vaughan, C.H.; Schwartz, G.J.; Song, C.K. Sensory and sympathetic nervous system control of white adipose tissue lipolysis. Mol. Cell. Endocrinol. 2010, 318, 34-43. [CrossRef] [PubMed]

39. Bowers, R.R.; Festuccia, W.T.L.; Song, C.K.; Shi, H.; Migliorini, R.H.; Bartness, T.J. Sympathetic innervation of white adipose tissue and its regulation of fat cell number. Am. J. Physiol. Regul. Integr. Comp. Physiol. 2004, 286, 1167-1175. [CrossRef] [PubMed]

40. Caron, A.; Richard, D. Neuronal systems and circuits involved in the control of food intake and adaptive thermogenesis. Ann. N. Y. Acad. Sci. 2017, 1391, 35-53. [CrossRef]

41. Lieu, L.; Chau, D.; Afrin, S.; Dong, Y.; Alhadeff, A.L.; Betley, J.N.; Williams, K.W. Effects of metabolic state on the regulation of melanocortin circuits. Physiol. Behav. 2020, 224, 113039. [CrossRef]

42. Baver, S.B.; Hope, K.; Guyot, S.; Bjørbaek, C.; Kaczorowski, C.; O'Connell, K.M.S. Leptin modulates the intrinsic excitability of AgRP/NPY neurons in the arcuate nucleus of the hypothalamus. J. Neurosci. 2014, 34, 5486-5496. [CrossRef]

43. Bastard, J.P.; Maachi, M.; Lagathu, C.; Kim, M.J.; Caron, M.; Vidal, H.; Capeau, J.; Feve, B. Recent advances in the relationship between obesity, inflammation, and insulin resistance. Eur. Cytokine Netw. 2006, 17, 4-12.

44. Gregor, M.F.; Hotamisligil, G.S. Inflammatory mechanisms in obesity. Annu. Rev. Immunol. 2011, 29, 415-445. [CrossRef]

45. Cai, D.; Yuan, M.; Frantz, D.F.; Melendez, P.A.; Hansen, L.; Lee, J.; Shoelson, S.E. Local and systemic insulin resistance resulting from hepatic activation of IKK- $\beta$ and NF-KB. Nat. Med. 2005, 11, 183-190. [CrossRef] [PubMed]

46. Tang, L.; Okamoto, S.; Shiuchi, T.; Toda, C.; Takagi, K.; Sato, T.; Saito, K.; Yokota, S.; Minokoshi, Y. Sympathetic nerve activity maintains an anti-inflammatory state in adipose tissue in male mice by inhibiting TNF- $\alpha$ gene expression in macrophages. Endocrinology 2015, 156, 3680-3694. [CrossRef] [PubMed]

47. Seino, Y.; Fukushima, M.; Yabe, D. GIP and GLP-1, the two incretin hormones: Similarities and differences. J. Diabetes Investig. 2010, 1, 8-23. [CrossRef]

48. Bell, G.I.; Santerre, R.F.; Mullenbach, G.T. Hamster preproglucagon contains the sequence of glucagon and two related peptides. Nature 1983, 302, 716-718. [CrossRef]

49. Schmidt, W.E.; Siegel, E.G.; Creutzfeldt, W. Glucagon-like peptide-1 but not glucagon-like peptide-2 stimulates insulin release from isolated rat pancreatic islets. Diabetologia 1985, 28, 704-707. [CrossRef]

50. Kawano, Y.; Nakae, J.; Watanabe, N.; Kikuchi, T.; Tateya, S.; Tamori, Y.; Kaneko, M.; Abe, T.; Onodera, M.; Itoh, H. Colonic pro-inflammatory macrophages cause insulin resistance in an intestinal Ccl2/Ccr2-dependent manner. Cell. Metab. 2016, 24, 295-310. [CrossRef] [PubMed]

51. Salinero, A.E.; Anderson, B.M.; Zuloaga, K.L. Sex differences in the metabolic effects of diet-induced obesity vary by age of onset. Int. J. Obes. 2018, 42, 1088-1091. [CrossRef] [PubMed]

52. Narimatsu, Y.; Iwakoshi-Ukena, E.; Fukumura, K.; Shikano, K.; Furumitsu, M.; Morishita, M.; Bentley, G.E.; Kriegsfeld, L.J.; Ukena, K. Hypothalamic overexpression of neurosecretory protein GL leads to obesity in male C57BL/6J mice. Neuroendocrinology 2021. [CrossRef] [PubMed]

53. Nagy, C.; Einwallner, E. Study of in vivo glucose metabolism in high-fat diet-fed mice using oral glucose tolerance test (OGTT) and insulin tolerance test (ITT). J. Vis. Exp. 2018, 131, 56672. [CrossRef] [PubMed]

54. Franklin, K.B.J.; Paxinos, G. The Mouse Brain in Stereotaxic Coordinates; Academic Press: Boston, MA, USA; Elsevier: Amsterdam, The Netherlands, 1997. 